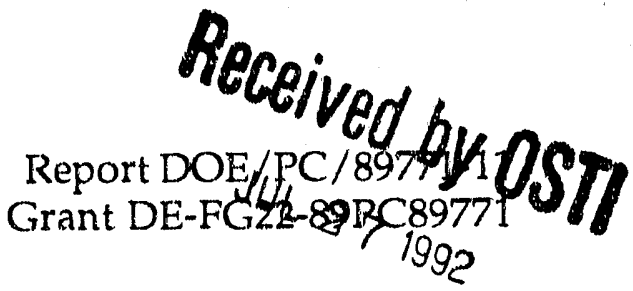

ELEVENTH QUARTER REPORT

April 1 - June 30, 1992

DOE/PC/89771--11

DE92 018438

\title{
MECHANISM OF HYDRODENITROGENATION (Part 11) \\ BETA-HYDRYGEN ELIMINATION
}

\author{
Raul Miranda \\ Department of Chemical Engineering \\ University of Louisville \\ Louisville, KY 40292, USA
}

\section{MASTER}

DISTRIBUTION OF THIS DOCUMENT IS UNLIMITED

contents<smiles></smiles>

$\begin{array}{lr}\text { Abstract } & 2 \\ \text { Introduction } & 2 \\ \text { Experimental } & 4 \\ \text { Results and Discussion } & 6 \\ \text { Conclusions } & 9 \\ \text { Acknowledgements } & 9 \\ \text { References } & 10 \\ \text { Figures } & 11\end{array}$

\section{DISCLAIMER}

\begin{abstract}
This report was prepared as an account of worh sponsored by an agency of the United States Government. Neither the United States Government nor any agency thereof, not any of their employees. makes any warranty, express or insplied, or assumes any legal liability or respontibility for the accuracy, completeness, or usefulness of any information, apparatus, product, or process disclosed, or represents that its use would not infringe privately owned rights. Reference herein to any specific commercial product, process, or service by trade name, trademark, manufacturer, or otherwise does not necessarily constituie or imply its endorsement, recom. mendation, or favoring by the United States Government or any agency thereof. The views and opinions of authors expressed herein do not necessarily state or reflect those of the United States Government or any agency thereot.
\end{abstract}




\begin{abstract}
Adsorption and thermal desorption of piperidine from catalysts exchanged with deuterium were studied by diffuse reflectance infrared spectroscopy of adsorbed piperidine and mass spectrometry of the desorption product. Thus the nature of the interaction between the adsorbed piperidine and the surface $\mathrm{OH}$ was elucidated. It was possible to conclude that piperidine exchanges only the beta- $\mathrm{H}$ of its molecule with surface OD. The lability of such hydrogen and its degree of interaction with surface sites are strong evidence that on acidic catalysts piperidine may undergo Hofmann elimination during the hydrodenitrogenation reaction.
\end{abstract}

\title{
INTRODUCTION
}

Efficient nitrogen removal from heterocyclic aromatics in liquid fuels calls for the development of catalysts with better HDN activity than is available with the traditional $\mathrm{HDS}$ catalysts, such as $\mathrm{CoMo} /$ gamma- $\mathrm{Al}_{2} \mathrm{O}_{3}$ and $\mathrm{NiMo} /$ gamma- $\mathrm{Al}_{2} \mathrm{O}_{3}$. Over these catalysts, the first step is the partial or total hydrogenation of the heterocyclic ring -- at equilibrium at normal operating conditions -- and the rate-limiting step is the scission of the $\mathrm{C}-\mathrm{N}-\mathrm{C}$ bonds. Therefore an increase in the rate of C-N-C scission should produce an overall increase in the HDN yield. To alter the rate of such critical step, it is crucial to understand the mechanism by which it occurs.

In retrospective three general types of mechanisms have survived the pass of time: a so called hydrogenolysis mechanism, a beta-elimination mechanism and a nucleophilic ring opening mechanism (Fig. 1). In the hydrogenolysis mechanism the saturated cyclic amine becomes a bidentate ligand of a coordinatively unsaturated metal site (cus). The metal has to expand its coordination sphere to accept the nitrogen lone pair and the alpha-carbon sp-electron. The strain in the cycle is removed by ring opening at the alpha-carbon. Gas phase hydrogen is probably dissociated in another metalic site before it provokes the desorption of the linear amine by hydrogenolytic addition. The elimination mechanism does not require the addition of hydrogen or of hydrogen dissociation sites. However, it 
requires the presence of a strong Bronsted acid site to provide proton addition to and quaternization of $\mathrm{N}$. Following Hofmann elimination rules, the alfa carbonnitrogen bond weakens and a beta carbon loses a proton, so that the ring opens and alfa-beta carbons become pi-bonded. The presence of a Lewis base promotes the elimination of the beta hydrogen, and thus further weakening of $\mathrm{N}$-alfa carbon bond, and the formation of the pi bond between alfa and beta carbons. The elimination described is of E2 or electrophilic type, requiring the presence of a Lewis base next to the adsorbed piperidinium ion. On the other hand, after $\mathrm{N}$ quaternization a nucleophilic attack may occur on the alfa carbon, provoking ring opening. This mechanism has been postulated to explain the enhanced denitrogenation activity displayed by Mo oxide catalysts in the presence of $\mathrm{H}_{2} \mathrm{~S}$ added to the feed.

In this project it is proposed that the selectivity of the HDN reaction can be affected by an alteration of the catalyst acidity since it is possible that the Bronsted acid-Lewis base catalyzed pathway is operative [1] in parallel with the hydrogenolysis of saturated C--N--C bonds. Such was the conclusion from the study done of the denitrogenation of piperidine [3], where it was demonstrated that Bronsted acid sites are active for the denitrogenation of $\mathrm{N}$-heterocycles, whereas Lewis acid sites are not.

In subsequent work [4-7] more evidence was sought of the elimination mechanism occurring in supported and reduced Mo catalysts. Varying acidity catalysts were well characterized structurally and chemically and probe reactions were studied (piperidine and pyridine HDN). Although indirect evidence was found of the promoting effect acidity has on HDN selectivity, direct evidence of the elimination mechanism is still lacking.

Therefore during this quarter, the surface of acidic and non-acidic catalysts was deuterated to exchange surface $\mathrm{OH}$ with $\mathrm{D}$, piperidine was pulsed over the deuterated catalysts, and evidence of deuterium exchange or addition was sought in the products of desorption. The technique of D-exchange was developed and tested in previous quarters [8-9] and was utilized to elucidate the adsorbed state of piperidine on supported Mo catalysts [10]. 


\section{EXPERIMENTAL}

\section{Synthesis of Supports and Supported Molybdena}

Silica-aluminas were prepared with a range of composition from $10-90 \mathrm{wt} \%$ silica. Separately, pure silica and gamma-alumina were also synthesized from the same precursors as the silica-aluminas. The supports were characterized by BET surface area, ammonia chemisorption and TPD, and IR of adsorbed pyridine. Details of the preparation and characterization results were given before [2].

Supported molybdena was prepared by incipient impregnation method from ammonium heptamolybdate, and were dried and calcined according to the technique described previously [4]. Several loadings were generated of which only the $8 \mathrm{wt} \%$ molybdena will be discussed in this report. The oxidic catalysts were prereduced in $50 \mathrm{ml} / \mathrm{min} \mathrm{H}_{2}$ at $400^{\circ} \mathrm{C}$ for 4 hours in a fixed-bed microreactor. Subsequently the powder was lightly compressed into a $13 \mathrm{~mm}$ pellet and rereduced in situ in the DRIFT cell, by flowing $\mathrm{H} 2$ at $400^{\circ} \mathrm{C}$ for 1 hour.

\section{Deuterium Exchange}

The exchange was effected with $D_{2}$ inside the DRIFTS cell equipped with environmental chamber and described before [5]. A catalyst pellet was made with 100 $\mathrm{mg}$ of powder compressed at about 200-500 psig for about $5 \mathrm{~min}$. No additive was used in these pellets. The pellet was rereduced as described above. Finally, the sample was evacuated at $400^{\circ} \mathrm{C}$ during 1 hour (10-5 Torr) to remove gas phase hydrogen.

For the exchange using $\mathrm{D}_{2}, 2 \mathrm{~atm}$ of gas was kept in the cell maintained at $400^{\circ} \mathrm{C}$ during 1 hour. The temperature was reduced to $150^{\circ} \mathrm{C}$ under pressure, followed by evacuation at $150^{\circ} \mathrm{C}$ during 1 hour. DRIFT spectra were recorded under $\mathrm{H}_{2}$ and $\mathrm{D}_{2}$ atmostpheres and under vacuum at 150 and $400^{\circ} \mathrm{C}$.

\section{Piperidine Adsorption and Desorption}

Piperidine was purified by distillation and was kept dry on a bed of molecular sieves and $\mathrm{KOH}$. A 0.5 microl pulse of piperidine was injected over the catalyst held under vacuum at $150^{\circ} \mathrm{C}$. Infrared peaks of the adsorbed species appeared 
immediately. After $30-60$ min under vacuum at $150^{\circ} \mathrm{C}$ the spectrum was recorded. Then the temperature was raised quickly to $400^{\circ} \mathrm{C}$, and kept for $1 \mathrm{~h}$ before recording another IR spectrum.

\section{Mass Spectrometry of Desorption Products}

The desorption products were sampled just above the catalyst pellet held inside the DRIFT cell, by means of a quartz capillary column that was directly connected to a mass spectrometer. The UTI $100 \mathrm{C}$ quadrupole mass spec was operated typically at a pressure of 10-7 Torr produced by an ion pump. About $1 \mathrm{ml} / \mathrm{min}$ of gas was sampled from the DRIFT cell which was maintained at about $10^{-3}$ Torr by a turbomolecular pump. The capillary tube fed the gas directly into the electron ionization chamber of the mass spectrometer. The electron ionization potential was kept at $70 \mathrm{eV}$. Continuous scanning of $\mathrm{m} / \mathrm{z}$ between 1 and 100 was performed at a rate of about $2 \mathrm{~m} / \mathrm{z}$ per second. Faster scanning rates were unnecessary because the desorption dynamics was very slow. In addition, this slow scanning allowed high sensitivity. The background was kept low by continuous baking of all the vacuum chamber at a temperature of $100^{\circ} \mathrm{C}$. 
Report DOE/PC/89771-11

\section{RESULTS AND DISCUSSION}

Fig. 2 gives the DRIFT spectra of $8 \mathrm{wt} \%$ molybdena supported on $75 \%$ silicaalumina and treated as indicated in the figure. The observed bands match those previously described [10,12]. The band at $3744 \mathrm{~cm}^{-1}$ belongs to the isolated silanol groups Si-OH while the broad band between 3700 and $3300 \mathrm{~cm}^{-1}$ belongs to the Hbonded silanols. After exchange (Fig. 3), new bands at $2757 \mathrm{~cm}^{-1}$ and $2720-2400 \mathrm{~cm}^{-1}$ appear, and they correspond to the isolated and deuterium-bonded OD groups, respectively. The group of bands between 3600 and $3700 \mathrm{~cm}^{-1}$ are enhanced by the $\mathrm{OH}$ groups present on alumina [10]. The broadness of the bands in these catalysts is due to the existence of several types of surface hydroxyl groups on the silica-alumina [13-15]. The bands between 3300 and $3600 \mathrm{~cm}^{-1}$ are themselves greatly enhanced by the appearance of new hydroxyl groups associated to molybdena, and probably present at the interface between support and molybdena [10]. After the hydrogen and vacuum treatments indicated in Fig. 2, a pulse of piperidine provokes the appearance of the typical adsorbate bands at 2864 and $2944 \mathrm{~cm}^{-1}$ which belong to $\mathrm{CH}_{2}$ stretching vibrations [11]. As seen before in the case of pure silica and silicasupported molybdena, piperidine interacts with the silanols of the silica-alumina surface. The interaction is strong as observed by the residual piperidine adsorbed even after desorption at $400^{\circ} \mathrm{C}$.

The nature of the interaction is more clearly seen in Fig. 3, which describes the adsorption and desorption of piperidine from D-exchanged silica-alumina surface. The sharp Si-OD band $\left(2757 \mathrm{~cm}^{-1}\right)$ is decreased after adsorption (fifth spectrum), and so is the broad band that we have assigned to OD groups at interfacial sites $\left(2500-2700 \mathrm{~cm}^{-1}\right)$. After desorption at $400^{\circ} \mathrm{C}$ (last spectrum) a minor restoration of the $2757,2600-2700(\mathrm{OD})$ and $3744 \mathrm{~cm}^{-1}$ (Si-OH) bands occur, while substantial amount of piperidine remains adsorbed. As shown before [10] only $\mathrm{H}_{2}$ flow at $400^{\circ} \mathrm{C}$ is able to completely desorb the piperidine and restore the $\mathrm{Si}-\mathrm{OH}$ bands. The piperidine that desorbs at $400^{\circ} \mathrm{C}$ under vacuum is possibly carrying with it the deuterium lost from the surface. This point was investigated next by monitoring the desorption products by mass spectrometry.

Fig. 4 is the mass spectrum of gas phase piperidine obtained by electron impact ionization at $70 \mathrm{eV}$. The parent peaks are at $\mathrm{m} / \mathrm{z}: 84$ and 85 , and there are main daughter peaks at 70,55-57 and 39-44. Such distribution is shown qualitatively in Table 1 . 
Fig. 5 is the mass spectrum of the species desorbing at 150 and $400^{\circ} \mathrm{C}$ under vacuum (Fig. 3) after having exchanged the catalyst with deuterium and having pulsed piperidine at $150^{\circ} \mathrm{C}$. Both desorption products at 150 and $400^{\circ} \mathrm{C}$ are identical, and their mass spectrum corresponds closely to that of piperidine (Fig. 4). Qualitative comparison of the observed peaks is given in Table 1.

Table 1

Main Peaks in Gas-Phase and Desorbed Piperidine

\begin{tabular}{cr} 
Gas Phase & Desorbed \\
\hline & 29 \\
39 & 30 \\
41 & 39 \\
42 & 41 \\
43 & 42 \\
44 & 43 \\
54 & 44 \\
55 & 54 \\
56 & 55 \\
57 & 56 \\
70 & 57 \\
84 & 70 \\
85 & 84 \\
& 85 \\
- & 86 \\
\hline
\end{tabular}

The major difference, and the one that deserves comment, is the appearance of 85-86 as the parent peaks in the desorbate as opposed to 84-85 in the piperidine feed. This result can be easily interpreted as the D-exchange of a single hydrogen in piperidine. Therefore, the loss of OD band in the infrared (Fig. 3) is actually due to exchange with piperidine.

A question arises as to where in the molecule has the exchange occurred. Since under the conditions of the experiment only a single exchange is fast, it is expected that the location of the exchange will indicate which atom in piperidine has a labile hydrogen and has also the possibility of interacting with surface $\mathrm{OH}$ 
(OD). For such reason we examined the mechanism of piperidine fragmentation by electron impact, as described by Duffield et al. [16], and shown in Fig. 6 .

The possible exchange locations are four: $N$, and $\alpha, \beta, \gamma-C$. According to Fig. 6 it is possible to discriminate the location of the exchange by identifying the unique $\mathrm{m} / \mathrm{z}$ that would be observed under each possible exchange. Such unique masses and the actually observed masses are given in Table 2.

Table 2

Fragment Masses for Possible Locations of Deuterium Exchange in Piperidine

\begin{tabular}{ccccl}
$\alpha-C$ & $\beta-C$ & $\gamma-C$ & $N$ & Observed \\
\hline 86 & 86 & 86 & 86 & yes \\
& 85 & 85 & 85 & yes \\
71 & & 71 & 71 & no \\
58 & & & 58 & no \\
31 & & & 31 & no \\
45 & & & 45 & no \\
\hline
\end{tabular}

As Table 2 indicates only $\beta-C$ exchange agrees with the observed fragmentation pattern. Thus the hydrogen that is most labile in adsorbed piperidine is located at the beta position. Furthermore, this is the location that is able to interact efficiently with surface OD.

Further experiments similar to the one described for silicaalumina/supported molybdenum were performed for silica, alumina, molybdena/silica and molybdena/alumina. Only the supported molybdena on silica and silica-alumina catalysts are able to exchange deuterium into piperidine under the conditions described here. As previously discussed [10-11] the supported molybdena catalysts (including the alumina-supported) chemisorb piperidine strongly and show (in the infrared) interaction between $O H(O D)$ and adsorbed piperidine. However, only the silica-supported and silica-alumina-supported catalysts show the characteristic $3744(2757) \mathrm{cm}^{-1} \mathrm{OH}(\mathrm{OD})$ that is drastically depleted upon desorption of piperidine. These observations afford the conclusion that the Dexchanging piperidine is strongly adsorbed on Mo cus that are located in proximity to Si-OD, such as the interfacial sites Si-OD-Mo. 


\section{CONCLUSIONS}

Diffuse reflectance infrared spectroscopy of adsorbed piperidine and mass spectrometry of the desorption product were applied to study the nature of the interaction between the adsorbed piperidine and the surface $\mathrm{OH}$. It was possible to conclude that piperidine exchanges a single $\mathrm{H}$ of its molecule with surface $\mathrm{OD}$, and that that $\mathrm{H}$ is the beta-hydrogen. This happens only on catalysts that contain strong adsorption sites for piperidine, such as Mo cus, located in proximity to $\mathrm{Si}-\mathrm{OH}$ sites, such as those present on silica and silica-alumina at the interface with molybdena. The beta-hydrogen exchange indicates that such hydrogen is labile and is in close contact with surface sites, thus it may be eliminated according a Hofmann elimination mechanism.

\section{ACKNOWLEDGEMENTS Funding}

This work was carried out with funds from DOE (Grant DE-FG22-89PC89771), partial support from NSF (Grant No. RII-8610671) and from the Commonwealth of Kentucky (EPSCoR Program).

\section{Personnel}

Jorge Marzari, PhD student 


\section{REFERENCES}

1. N. Nelson and R. B. Levy, J. Catal. 58(1979)485

2. R. Miranda, "Mechanism of Hydrodenitrogenation. Part I: Preparation and Characterization of Acidic Supports", DOE Report DOE/PC/89771-1, January 1990.

3. R. Miranda, "Mechanism of Hydrodenitrogenation. Part II: Piperidine Denitrogenation over Silica-Aluminas", DOE Report DOE/PC/89771-2, April 1990.

4. R. Miranda, "Mechanism of Hydrodenitrogenation. Part III: Preparation and Characterization of Acidic Molybdena Catalysts", DOE Report DOE/PC/897713, July 1990.

5. R. Miranda, "Mechanism of Hydrodenitrogenation. Part IV: Infrared Spectroscopy of Acidic Molybdena Catalysts", DOE Report DOE/PC/89771-4, October 1990.

6. R. Miranda, "Mechanism of Hydrodenitrogenation. Part V: X-Ray Diffraction of Supported Molybdena Catalysts", DOE Report DOE/PC/89771-5, January 1991.

7. R. Miranda, "Mechanism of Hydrodenitrogenation. Part VI: HDN of Pyridine over Acidic Molybdena Catalysts", DOE Report DOE/PC/89771-6, April 1991.

8. R. Miranda, "Mechanism of Hydrodenitrogenation. Part VII: Low Temperature Oxygen Chemisorption of Acidic Molybdena Catalysts", DOE Report DOE/PC/89771-7, June 1991.

9. R. Miranda, "Mechanism of Hydrodenitrogenation. Part VIII: H2-D2 Exchange in Non-Acidic and Acidic Supports", DOE Report DOE/PC/89771-8, September 1991.

10. R. Miranda, "Mechanism of Hydrodenitrogenation. Part IX: H2-D2 Exchange in Reduced Mo Catalysts", DOE Report DOE/PC/89771-9, December 1991. 
11. R. Miranda, "Mechanism of Hydrodenitrogenation. Part X: Adsorption of Piperidine on Reduced Mo Catalysts", DOE Report DOE/PC/89771-10, March 1992.

12. E. Baumgarten, C. Lentes-Wagner, R. Wagner, J. Molec. Catal. 50, 153-65 (1989)

13. J.L. Carter, P.J. Lucchesi, P. Corneil, D.J.C. Yates, J.H. Sinfelt, J. Phys. Chem. 69, 3070-4 (1965)

14. Y. Amenomiya, J. Catal. 22, 109-22 (1971)

15. H. Knozinger, P. Ratnasamy, Catal. Rev. Sci. Eng. 17, 31 (1978)

16. A.M. Duffield, H. Budzikiewicz, D.H. Williams, C. Djerassi, JACS, 87, 810-816 (1965)

\section{FIGURES}

Fig. 1 Classically Postulated Mechanisms of Ring Opening of Cyclic Aliphatic Amines.

Fig. 2 Diffuse reflectance IR spectra of reduced $8 \mathrm{wt} \%$ molybdena/75\% silicaalumina. Adsorption and desorption of piperidine.

Fig. 3 Diffuse reflectance IR spectra of reduced and deuteriumexchanged $8 \mathrm{wt} \%$ molybdena/ $75 \%$ silica-alumina.

Adsorption and desorption of piperidine.

Fig. 4 Mass spectrum of pure piperidine, obtained by electron impact ionization.

Fig. 5 Mass spectrum of piperidine desorbed at two temperatures from deuterium-exchanged $8 \mathrm{wt} \%$ molybdena $/ 75 \%$ silica-alumina.

Fig. 6 Mechanism of mass fragmentation of piperidine under electron impact ionization [16]. 
Hydrogenolysis

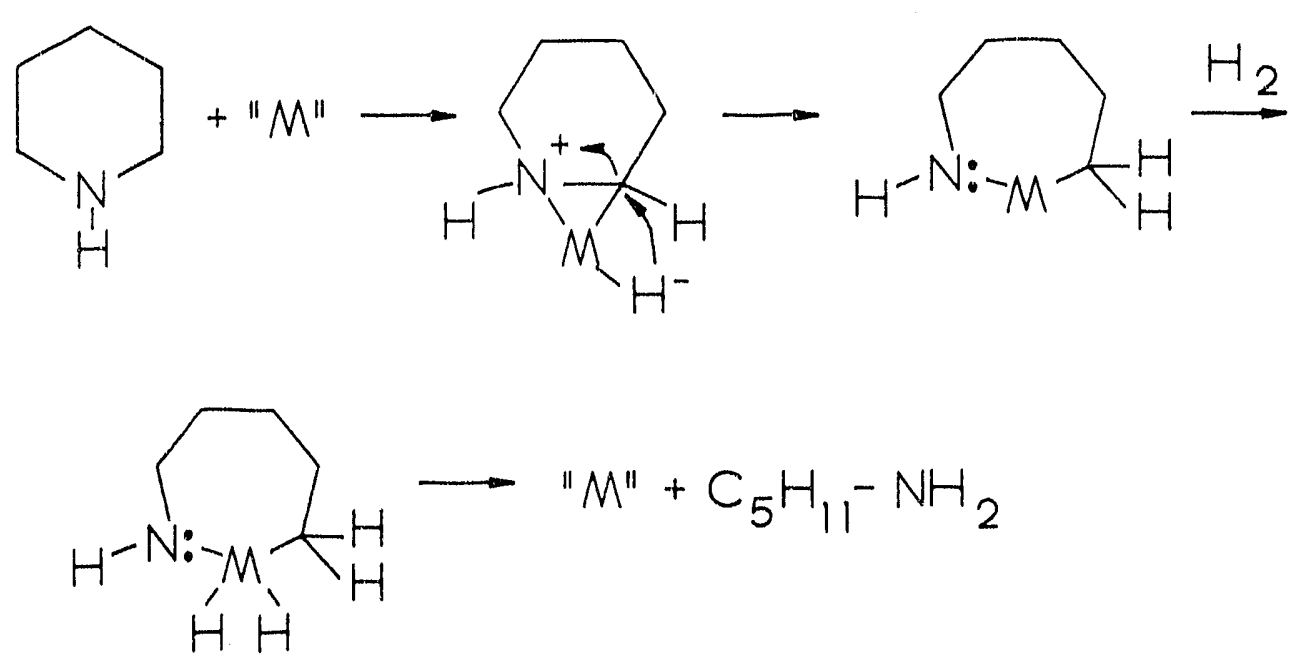

Elimination

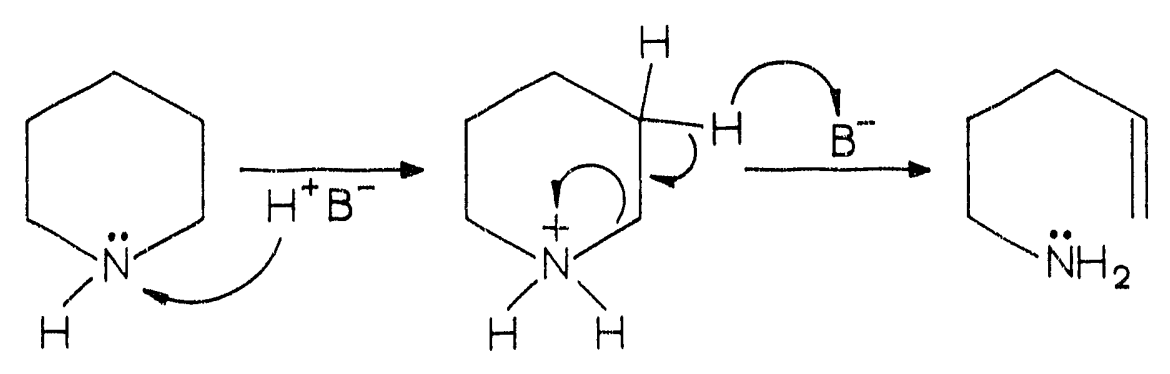

Nucleophilic ring opening

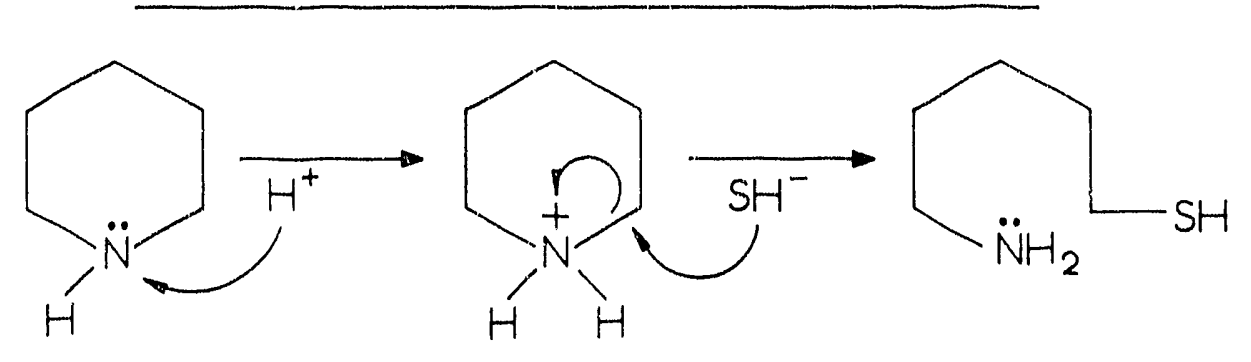




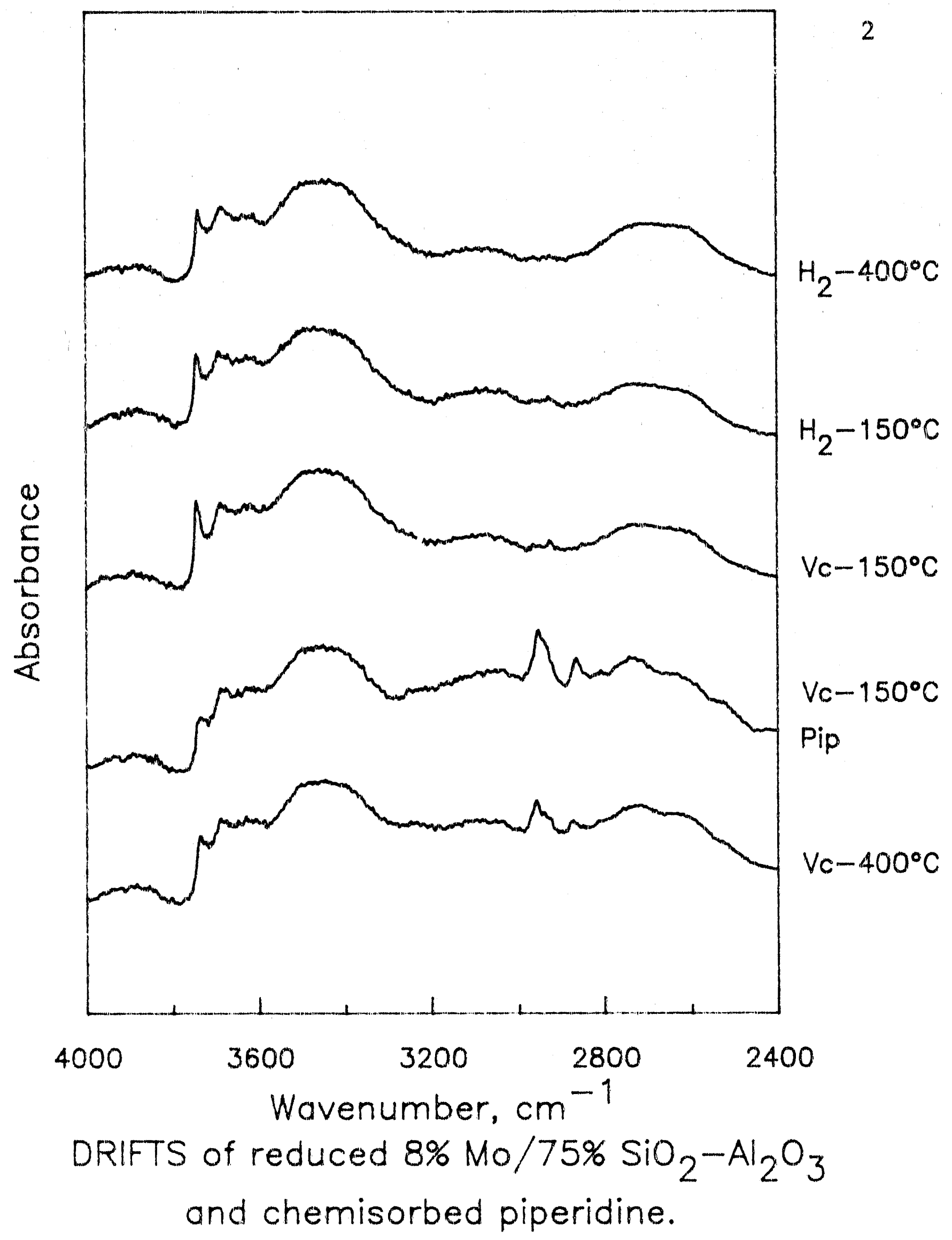




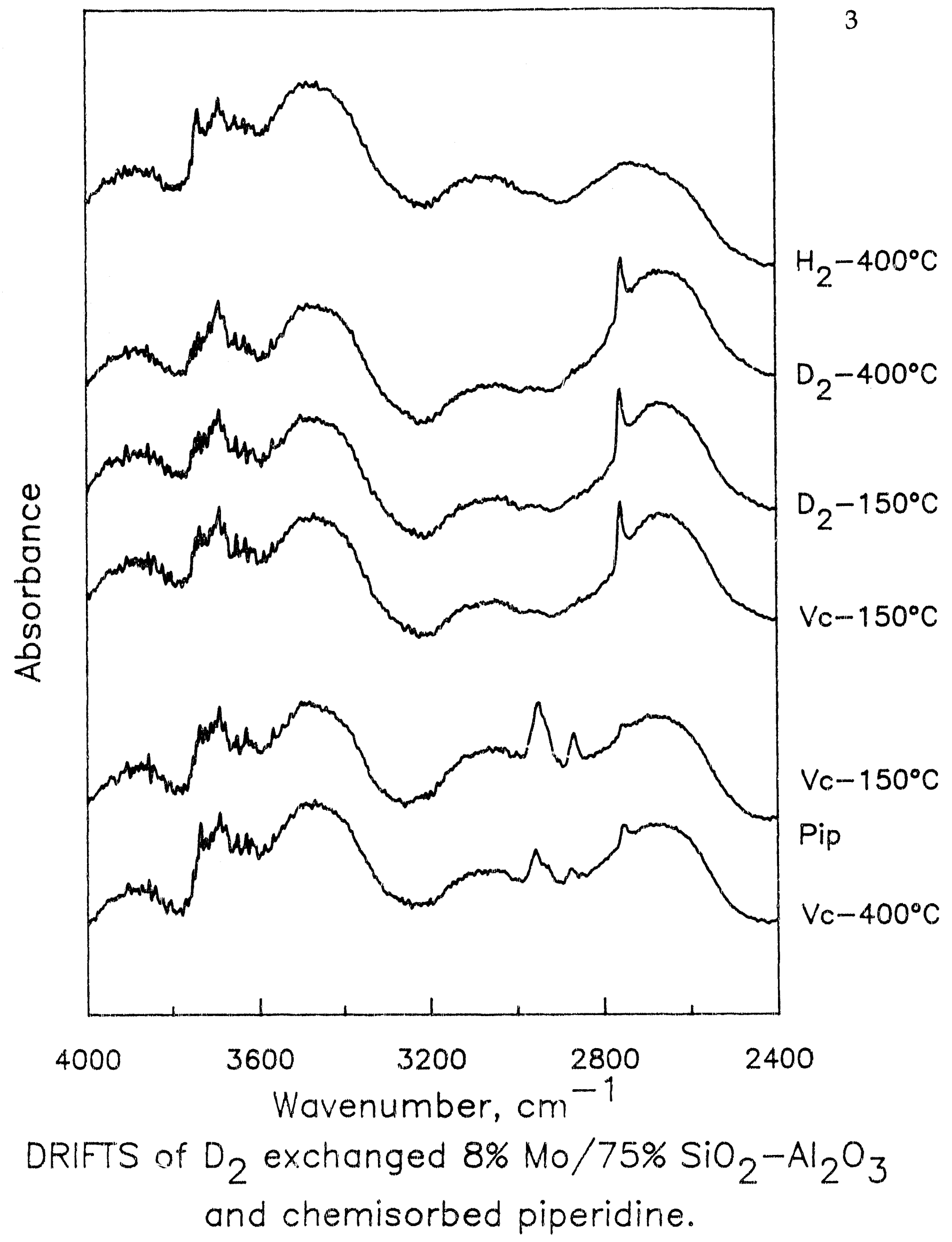




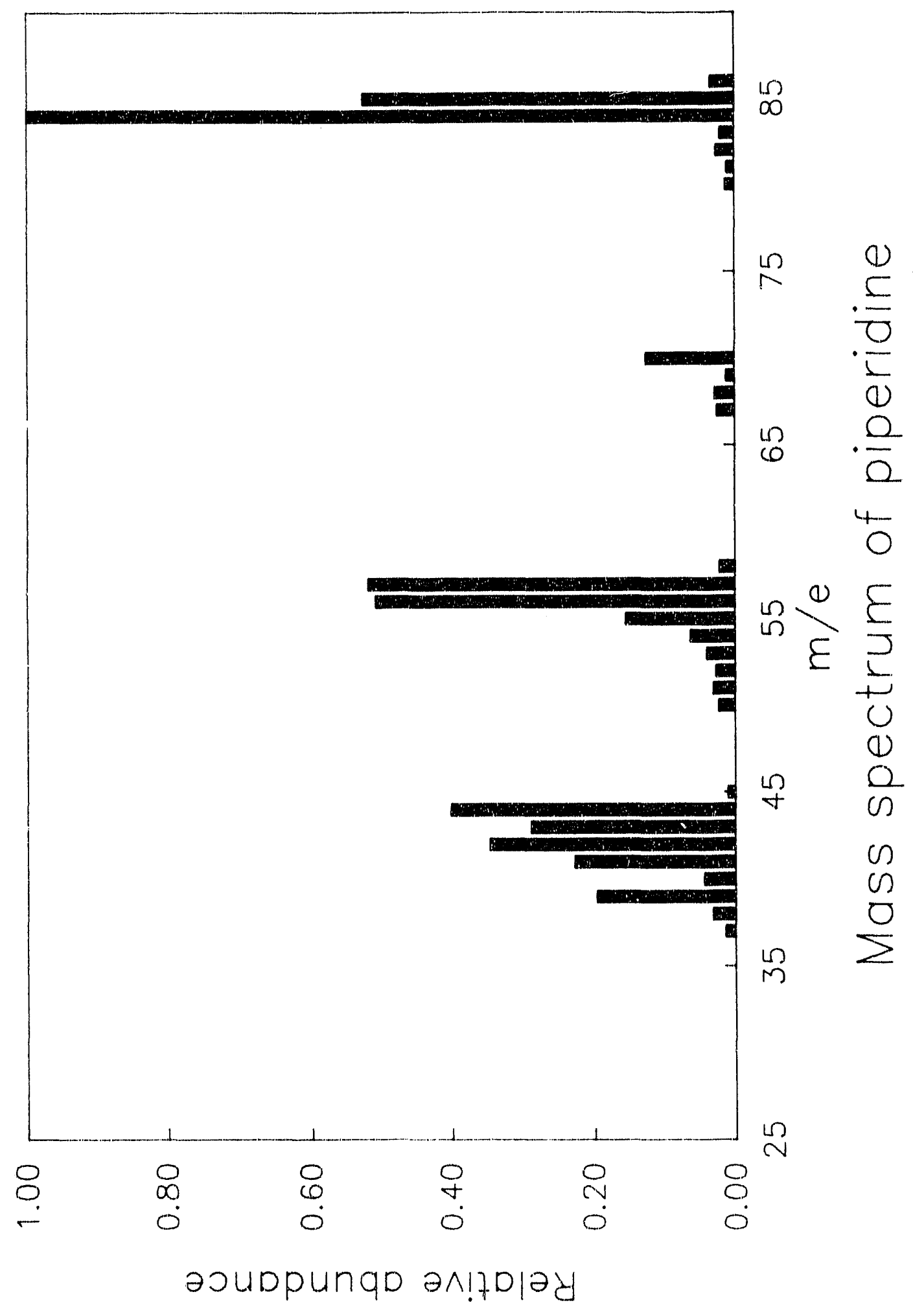




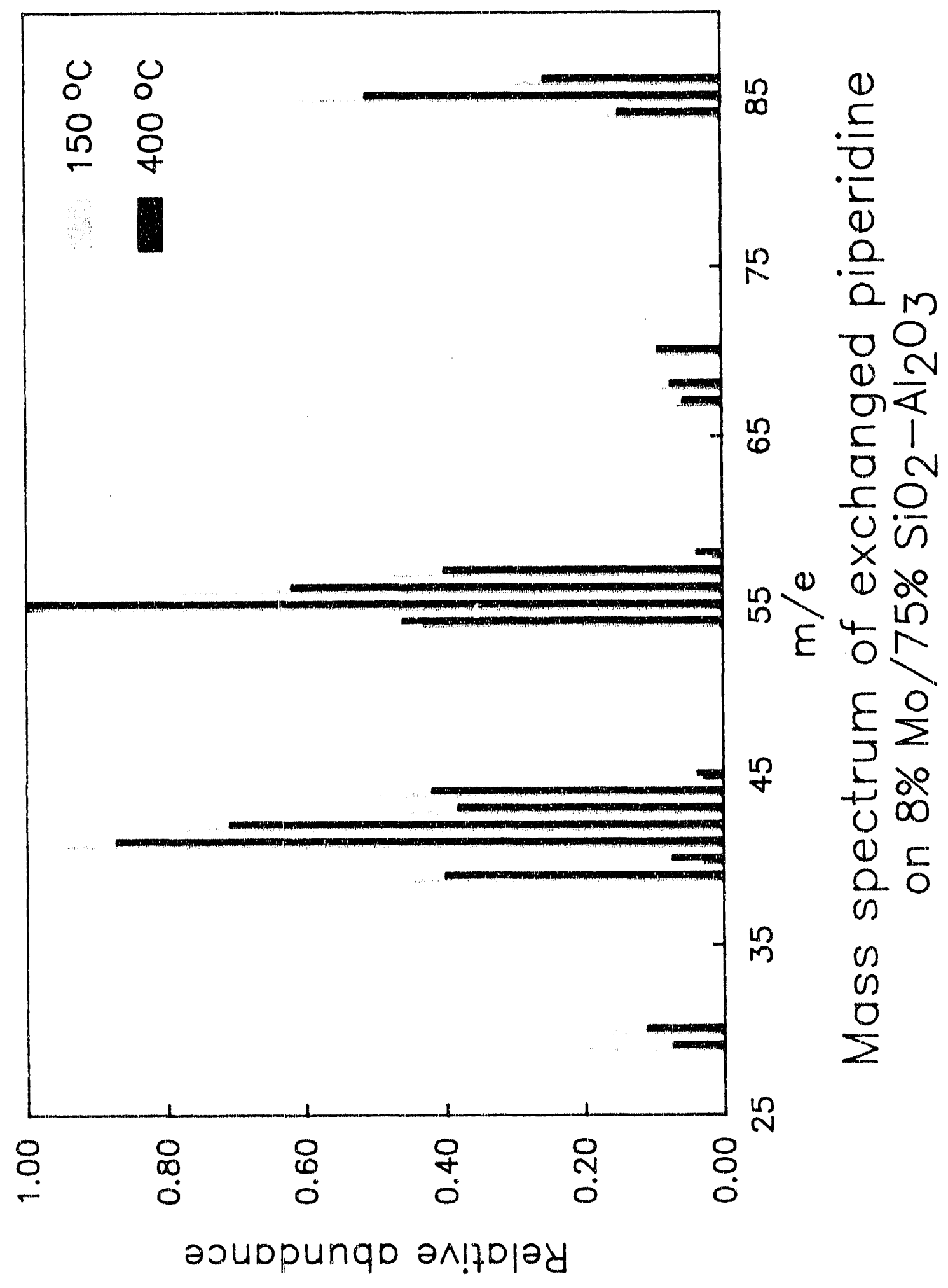




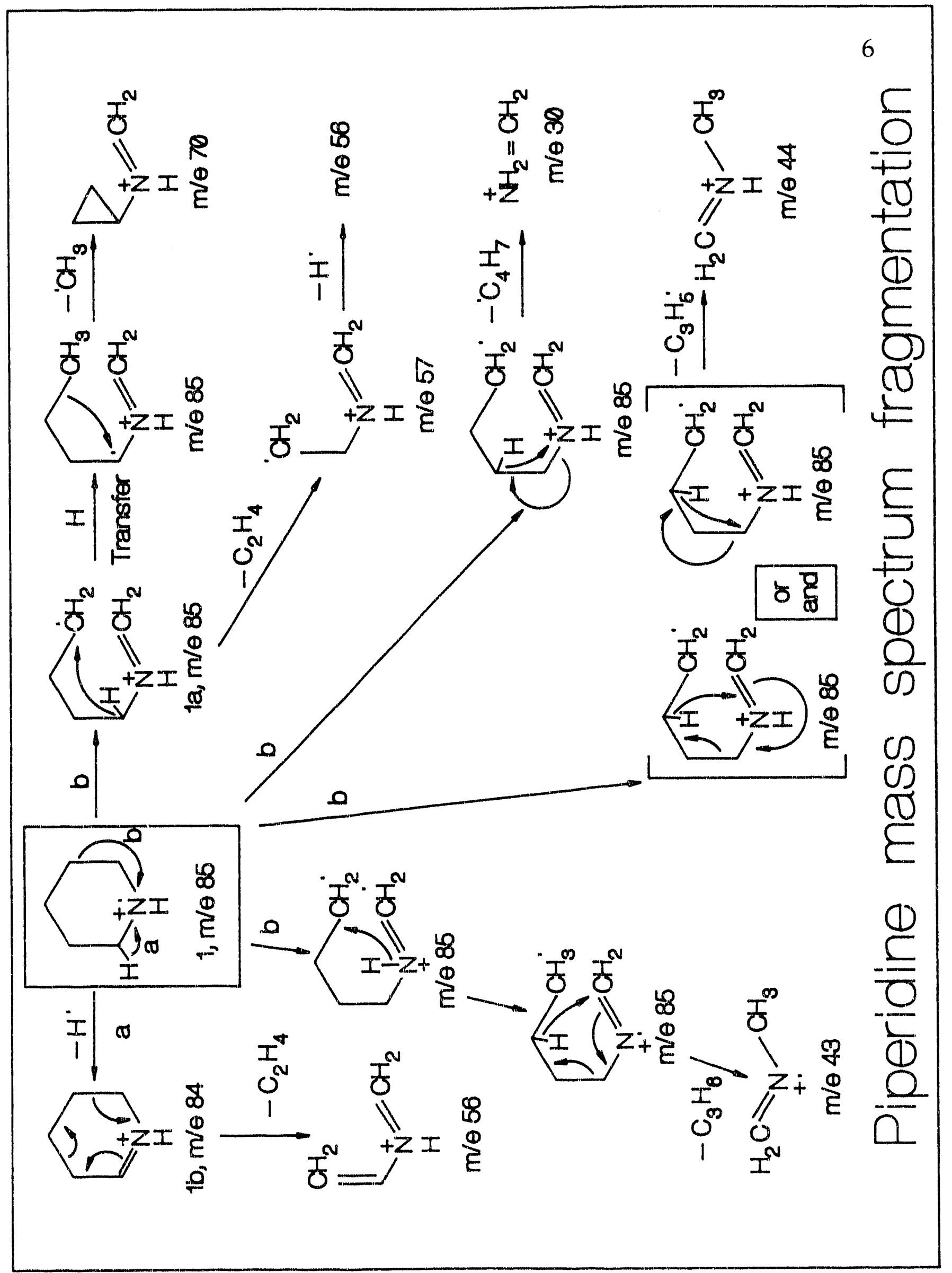



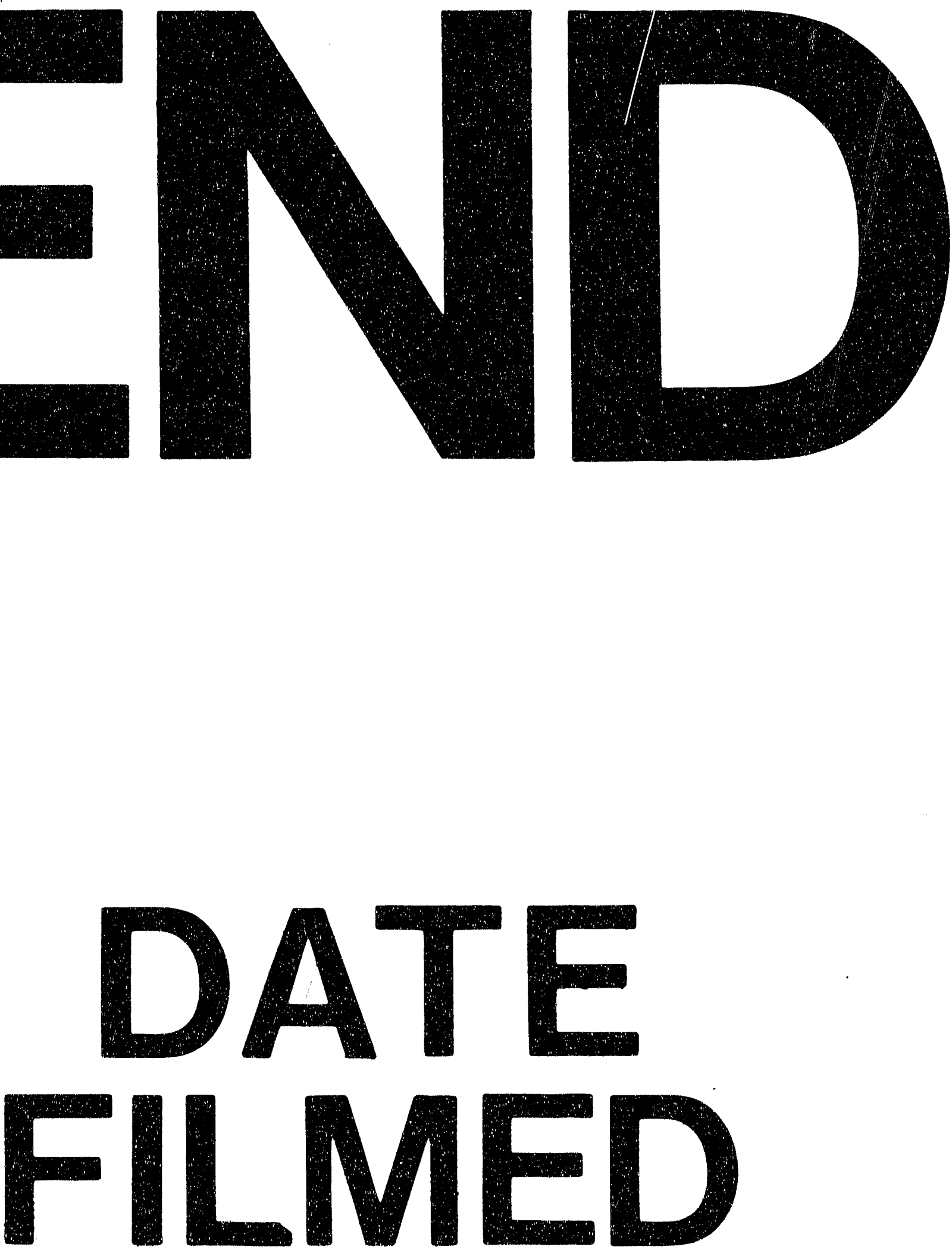

$\pm$

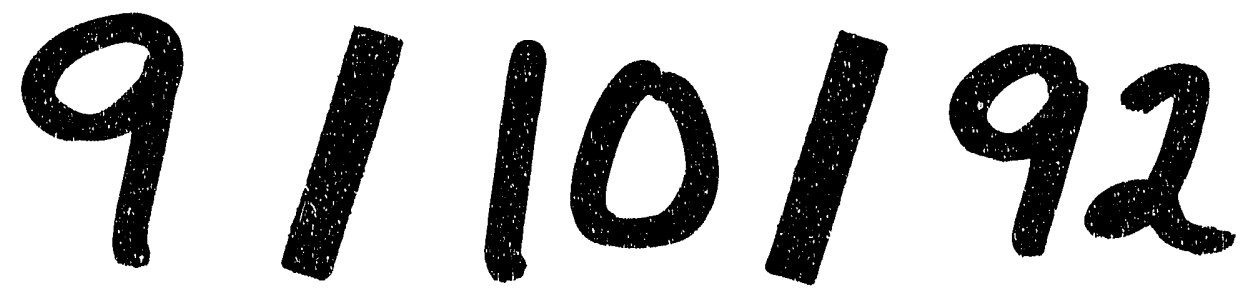


